\title{
Contribuição genética na produtividade do arroz irrigado em Minas Gerais no período de 1998 a 2010
}

\author{
Júlio César DoVale $\left({ }^{(*)}\right)$; Plínio César Soares $\left({ }^{2}\right)$; Vanda Maria Oliveira Cornélio $\left({ }^{2}\right)$; Moizés Souza Reis $\left({ }^{2}\right)$; \\ Vanderley Borges ( $\left.{ }^{3}\right)$; Rayane Barcelos Bisi $\left({ }^{4}\right)$; Antônio Alves Soares ( $\left.{ }^{5}\right)$; Roberto Fritsche-Neto $\left({ }^{4}\right)$ \\ (') Universidade Federal do Ceará (UFC), Departamento de Fitotecnia, 60021-970 Fortaleza (CE), Brasil. \\ (2) Empresa de Pesquisa Agropecuária de Minas Gerais (EPAMIG), 31170-495 Belo Horizonte (MG), Brasil. \\ (3) Universidade Federal do Acre (UFAC), Centro de Ciências Biológicas e da Natureza, 69915-900 Rio Branco (AC), Brasil. \\ (4) Universidade Federal de Viçosa (UFV), Departamento de Fitotecnia, 36571-000 Viçosa (MG), Brasil. \\ (5) Universidade Federal de Lavras (UFLA), Departamento de Agricultura, 37200-000 Lavras (MG), Brasil. \\ (*) Autor correspondente: juliocvale@gmail.com
}

Recebido: 1.\%/maio/2012; Aceito: 21/dez./2012

\begin{abstract}
Resumo
O objetivo desse estudo foi quantificar o ganho genético para produtividade de grãos do programa de melhoramento do arroz irrigado de Minas Gerais, no período de 1998 a 2010. Foram utilizados dados dos ensaios comparativos avançados realizados em quatro localidades diferentes de Minas Gerais. Nem todos os locais foram contemplados em todos os anos agrícolas e para estimativas com maior acurácia, utilizou-se o método de modelos mistos. O ganho genético para produtividade de grãos no período considerado foi de $107,42 \mathrm{~kg} \mathrm{ha}^{-1}$, o que representou uma proporção de $17,88 \%$ da estimativa total do progresso. Esse ganho correspondeu ao aumento de $8,95 \mathrm{~kg} \mathrm{ha}^{-1} \mathrm{ano}^{-1}$, ou ainda, aumento de 1,99\% em produtividade de grãos por ano. Apesar de o ganho genético ter sido satisfatório, novas alternativas de melhoramento podem ser empreendidas para que o incremento produtivo seja maior nos próximos anos.
\end{abstract}

Palavras-chave: Oryza sativa, progresso genético, obtenção de cultivares, REML/BLUP.

\section{Genetic contribution in yield of irrigated rice in Minas Gerais State between 1998 and 2010}

\section{Abstract}

The objective of this study was to quantify the genetic gain for grain yield of the breeding program of irrigated rice in Minas Gerais State, Brazil, in the period of 1998 to 2010. For this, data from advanced comparative trials performed in four different sites of Minas Gerais were analyzed. Some sites were not included in all crop years and thus a mixed model methodology was used to obtain more accurate estimates. The genetic gain for grain yield over the period was $107.42 \mathrm{~kg} \mathrm{ha}^{-1}$, which represented a proportion of $17.88 \%$ of the total progress estimative. This gain corresponds to an increase of $8.95 \mathrm{~kg} \mathrm{ha}^{-1} \mathrm{yr}^{-1}$ or even a $1.99 \%$ increase in grain productivity per year. Although the genetic gain has been satisfactory, new alternatives may be applied to improve the rice yield in coming years.

Key words: Oryza sativa, genetic progress, cultivar development, REML/BLUP.

\section{INTRODUÇÃO}

O programa de avaliação e seleção de linhagens de arroz irrigado no Estado de Minas Gerais é realizado pela parceria entre a Empresa de Pesquisa Agropecuária de Minas Gerais (EPAMIG), Embrapa Arroz e Feijão e a Universidade Federal de Lavras (UFLA), e constituído pelos Ensaios Comparativos Preliminares (ECPs) e Ensaios Comparativos Avançados (ECAs), que, em geral, denomina-se Ensaios de Valor de Cultivo e Uso (VCUs). Na primeira classe de ensaios, são selecionadas as melhores linhagens, para posteriormente serem avaliadas nos ECAs. As informaçóes obtidas nesses ensaios são decisivas para a identificação das linhagens com potencial para serem liberadas como novos cultivares (Atroch e Nunes, 2000).

O conhecimento do ganho genético é de fundamental importância em programas de melhoramento, pois permite averiguar seu sucesso, buscar novos métodos que venham a ampliar sua eficácia, orientar futuras açóes de pesquisa e reavaliar as estratégias empregadas (SoAres et al., 2005; Menezes Júnior et al., 2008). Normalmente, estimar o progresso genético em um programa de melhoramento significa verificar a contribuição efetiva do melhoramento genético, na elevação da média dos genótipos selecionados em um ano e testados no ano seguinte (Borges et al., 2009). 
Vencovsky et al. (1988) demonstraram que é possível utilizar os dados dos ECAs ou VCUs para estimação dos ganhos genéticos em produtividade de grãos. Neste contexto, diversos estudos foram realizados com arroz e objetivaram estimar os ganhos anuais, como Soares et al. (1999), Breseghello et al. (1999), Атroch e Nunes (2000) e Rangel et al. (2000). No entanto, a grande maioria de estudos dessa natureza baseia-se em estimativas de quadrados mínimos. Dessa forma, as análises são realizadas com valores fenotípicos que, em virtude dos elevados graus de desbalanceamentos (locais, repetiçôes, anos, genótipos, etc.) e da dinâmica dos programas com a inserção e exclusão de genótipos, inviabilizam a obtenção de estimativas fiéis do verdadeiro valor genético. Assim, métodos mais eficientes que permitam estimar os ganhos de um programa de melhoramento com maior acurácia, são extremamente importantes (Borges et al., 2009).

Um método atualmente mais eficiente na análise de dados balanceados ou não, é o da Máxima Verossimilhança Restrita/Melhor Preditor Linear Não-viesado (REML/BLUP) (Fritsche-Neto et al., 2010). Nesse método, efeitos de genótipos são considerados como de efeitos aleatórios e os de mais efeitos principais como de efeitos fixos. A técnica REML/BLUP envolve, simultaneamente, a predição dos valores genéticos e estimação de componentes de variância, sendo o procedimento ótimo de estimação/predição para estimação de componentes de variância/predição dos valores genéticos (RESENDE, 2002).

Diante do exposto, objetivou-se quantificar o ganho genético para produtividade de grãos do programa de melhoramento de arroz irrigado do Estado de Minas Gerais, no período de 1998 a 2010.

\section{MATERIAL E MÉTODOS}

Foram utilizados os dados dos Ensaios Comparativos Avançados do programa de melhoramento de arroz irrigado de Minas Gerais no período de 1998 a 2010. Os dados do ano agrícola 2008/2009 não foram considerados na análise, uma vez que o elevado índice pluviométrico (nebulosidade) desse ano reduziu significativamente a produtividade dos genótipos (cultivares e/ou linhagens) avaliados, inviabilizando dessa forma, sua comparação com a das outras safras.

Anualmente, no período mencionado, os genótipos que não tinham bom desempenho eram descartados e substituídos por outros. Os genótipos com bom desempenho foram mantidos em avaliação contínua e, dependendo de seu desempenho anual, poderiam ser avaliados por dois ou mais anos.

Os ensaios foram realizados em quatro localidades distribuídas em diferentes regióes do Estado de Minas Gerais que cultivam arroz irrigado. Contudo, nem todos os locais foram contemplados em todos os anos agrícolas (Tabela 1). O número de ensaios variou de um a quatro, totalizando 28. Anualmente, foram avaliados 25 genótipos, com exceçáa do ensaio de 1999 , quando se avaliaram 26. Assim, ao longo destes 12 anos agrícolas, foram avaliados 102 genótipos.

Todos os ensaios foram instalados em delineamento experimental de blocos ao acaso com quatro repetiçóes. As parcelas foram constituídas por cinco fileiras de $5 \mathrm{~m}$ de comprimento, espaçadas de $0,3 \mathrm{~m}\left(5 \times 1,5 \mathrm{~m}=7,5 \mathrm{~m}^{2}\right)$. Como área útil, foram considerados os $4 \mathrm{~m}$ centrais das três fileiras internas $\left(4 \times 0,9 \mathrm{~m}=3,6 \mathrm{~m}^{2}\right)$. Os tratos culturais foram realizados de acordo com o recomendado para a cultura para a região (SOARES et al., 2005).

Para a obtençáo dos componentes de variância e das estimativas dos parâmetros genéticos, submeteram-se os dados à análise por meio do método da Máxima Verossimilhança Restrita/Melhor Preditor Linear Não Viesado (REML/BLUP), conforme descrito por RESENDE (2002). Inicialmente, procederam-se as análises de deviance para locais dentro de cada ano, considerando o seguinte modelo:

$\mathrm{y}=\mathrm{Xr}+\mathrm{Zg}+\mathrm{Wi}+\mathrm{e}$

Tabela 1. Número de ensaios de valor de cultivo e uso (VCUs), locais e número de genótipos avaliados pelo programa de melhoramento de arroz irrigado em Minas Gerais, no período de 1998 a 2010, Minas Gerais, Brasil

\begin{tabular}{|c|c|c|c|c|c|c|}
\hline \multirow{2}{*}{ Anos } & \multicolumn{4}{|c|}{ Locais } & \multirow{2}{*}{ Número de ensaios } & \multirow{2}{*}{ Número de genótipos } \\
\hline & Janaúba & Lambari & Leopoldina & Prudente de Morais & & \\
\hline 1998 & 1 & 1 & 1 & 1 & 4 & 25 \\
\hline 1999 & 1 & 1 & 1 & & 3 & 26 \\
\hline 2000 & 1 & 1 & & 1 & 3 & 25 \\
\hline 2001 & & & 1 & 1 & 2 & 25 \\
\hline 2002 & 1 & & 1 & & 2 & 25 \\
\hline 2003 & 1 & & 1 & & 2 & 25 \\
\hline 2004 & 1 & & 1 & & 2 & 25 \\
\hline 2005 & & & 1 & & 1 & 25 \\
\hline 2006 & 1 & & 1 & & 2 & 25 \\
\hline 2007 & 1 & 1 & 1 & & 3 & 25 \\
\hline 2008 & 1 & & 1 & & 2 & 25 \\
\hline 2010 & & & 1 & 1 & 2 & 25 \\
\hline Total & 10 & 4 & 11 & 3 & 28 & 102 \\
\hline
\end{tabular}


em que: y é o vetor das médias fenotípicas dos genótipos; $\mathrm{r}$ é o vetor dos efeitos de repetição dentro de local (assumidos como fixos) somados à média geral; g é o vetor dos efeitos genotípicos (assumidos como aleatórios), em que, $g \sim N(0$, $G$ ), sendo $G=I \sigma_{g}^{2}$; i é o vetor da interação genótipo x local (assumidos como ăleatórios), em que, $i \sim N\left(0, I_{g l}\right)$, sendo $I_{g l}=I \sigma_{g l}^{2}$ ; e é o vetor de erros, sendo $e-N(0, R)$ e $R=I \sigma_{e}^{2}$. X, Z $\mathrm{Z}$ e W matrizes de incidência que relacionam, respectivamente, os efeitos de r, g e i ao vetor $\mathrm{y}$.

As equações de modelo misto para a predição de r, $\mathrm{g}$ e i equivalem a:

\section{$\left[\begin{array}{ccc}X^{\prime} X & X^{\prime} Z & X^{\prime} W \\ Z^{\prime} X & Z^{\prime} Z+\lambda_{1} & Z^{\prime} W \\ W^{\prime} X & W^{\prime} Z & W^{\prime} W+\lambda_{2}\end{array}\right]\left[\begin{array}{c}r \\ g \\ i\end{array}\right]=\left[\begin{array}{c}X^{\prime} y \\ Z^{\prime} Y \\ W^{\prime} y\end{array}\right]$}

em que, $\lambda_{1}=\frac{1-h_{g}^{2}-h_{i}^{2}}{h_{g}^{2}}$ e $\lambda_{2}=\frac{1-h_{g}^{2}-h_{i}^{2}}{h_{i}^{2}}$;

onde: $h_{\sigma}^{2}$ é a herdabilidade no sentido amplo dos genótipos; $h_{i}^{2}$ ế o coeficiente de determinação da interação genótipo x local.

Posteriormente, foi realizada a análise de deviance global envolvendo todos os anos, considerando o seguinte modelo:

$\mathrm{y}=\mathrm{Xa}+\mathrm{Zg}+\mathrm{Wu}+\mathrm{e}$

em que: y é o vetor das médias fenotípicas das genótipos; a é o vetor dos efeitos de repetição dentro de ano (assumidos como fixos) somados à média geral; g é o vetor dos efeitos genotípicos (assumidos como aleatórios), em que, $g \sim N(0$, $G)$, sendo $G=I \sigma_{g}^{2}$; u é o vetor da interaçấo genótipo x ano (assumidos como aleatórios), em que, $u-N\left(0, U_{g a}\right)$, sendo $U_{g a}=I \sigma_{g a}^{2}$; e é o vetor de erros, sendo $e-N(0, R)$ e $R=I \sigma_{e}^{2}$. X, $\mathrm{Z}^{g a} \mathrm{eW}$ matrizes de incidência que relacionam, respectivamente, os efeitos de a, g e u ao vetor $\mathrm{y}$.

As equaçóes de modelo misto para a predição de a, $\mathrm{g}$ e u equivalem a:

$$
\left[\begin{array}{lcl}
X^{\prime} X & X^{\prime} Z & X^{\prime} W \\
Z^{\prime} X & Z^{\prime} Z+\lambda_{1} & Z^{\prime} W \\
W^{\prime} X & W^{\prime} Z & W^{\prime} W+\lambda_{2}
\end{array}\right]\left[\begin{array}{l}
a \\
g \\
u
\end{array}\right]=\left[\begin{array}{c}
X^{\prime} y \\
Z^{\prime} Y \\
W^{\prime} y
\end{array}\right]
$$

em que, $\lambda_{1}=\frac{1-h_{g}^{2}-h_{u}^{2}}{h_{g}^{2}}$ e $\lambda_{2}=\frac{1-h_{g}^{2}-h_{u}^{2}}{h_{u}^{2}}$

onde: $h_{g}^{2}$ é a herdabilidade no sentido amplo dos genótipos; $h_{u}^{2}$ é o coeficiente de determinação da interação genótipo $\mathrm{x}$ ano.

Para a resolução das equaçóes de modelos mistos e a obtenção dos valores genéticos, os componentes de variância genéticos e não genéticos foram assumidos desconhecidos. Estes foram estimados pelo método REML, utilizando o pacote estatístico computacional SELEGEM-REML/BLUP (RESENDE, 2007).
Para se obter as estimativas do progresso genético, foram usados os valores genotípicos $(\hat{u}+\hat{g})$ obtidos em cada ano de avaliação. Esses valores consistem na previsão dos valores genéticos $(\hat{g})$ de cada genótipo, considerados como aleatórios, ajustando-os simultaneamente aos efeitos fixos $(\hat{u})$, para um número desigual de informaçôes de genótipos ao longo dos anos agrícolas. Assim, a flexibilidade do método de modelos mistos permite a obtenção de estimativas mais acuradas, principalmente no caso de dados desbalanceados, como a não avaliação dos genótipos em todos os locais dentro de cada ano (Fritsche-Neto et al., 2010).

Após se obter as estimativas dos valores genotípicos, foram estimadas as taxa de substituição genotípica e o progresso genético. Para isso, utilizou-se o aplicativo computacional em genética e estatística GENES (Cruz, 2006), por meio dos métodos descritas por Moresco et al. (2004) e VenCovsky et al. (1988) respectivamente. Pelo primeiro método foram estimadas as taxas dos genótipos incluídos (I), excluídos (E), mantidos (M) e avaliados (T) de um ano para o subsequente, por meios das seguintes equações (em porcentagem),

$\% I=\frac{100 I}{M+E+I}$,

$\% E=\frac{100 E}{M+E+I}$,

$\% M=\frac{100 M}{M+E+I}$

e $\% R=\frac{100 I}{M+I}$, em que:

$\mathrm{I}$ = número de genótipos incluídos no ano subsequente; $\mathrm{E}=$ número de genótipos excluídos no ano anterior e $\mathrm{M}=$ número de genótipos mantidos de um ano para o outro. Pelo segundo método, a estimativa do ganho genético foi obtida pelo contraste entre a média de todos os genótipos de um dado ano e a do ano anterior. Deste contraste, subtraiu-se o efeito do ano, estimado pela diferença entre a média do grupo de genótipos comuns nesses dois anos consecutivos. Assim, considerando-se dois anos consecutivos, o ganho genético é estimado pela diferença genética, conforme a expressão $g d_{21}=t d_{21}-e d_{21}$, em que: $t d_{21}=\left(Y_{2}-Y_{1}\right)$ é a diferença total entre a média de todos os genótipos avaliados no ano 2 e a média dos genótipos avaliados no ano 1, representadas por $Y_{2}$ e $Y_{1}$ respectivamente; $e d_{21}=\left(\bar{Y}_{(21) 2}-\bar{Y}_{(21) 1}\right)$ é a diferença ambiental entre as médias dos grupos de genótipos avaliados nos anos 2 e 1 representada por $\bar{Y}_{(21) 2}$ e $\bar{Y}_{(21) 1}$ respectivamente.

$\mathrm{O}$ aumento em produtividade foi estimado por meio da melhoria dos genótipos avaliados e das condiçôes ambientais, com base em "a" anos e " $\mathrm{a}-1$ " diferenças genéticas e ambientais entre cada par de anos avaliados. A soma de todos os valores de $g d$ e $e d$ representam o acréscimo em produtividade no período considerado no estudo, sendo o resultado da melhoria genotípica e ambiental. Para obter 
o aumento na média por ano, o progresso acumulado foi dividido pelo número de anos do período considerado. Essa última estimativa dividida pela média geral do experimento do primeiro ano (média de referência) e multiplicada por 100, forneceu o ganho genético anual médio em porcentagem (VenCOVsKY et al., 1988).

\section{RESULTADOS E DISCUSSÃO}

Os genótipos diferiram significativamente, pela análise de deviance, para produtividade de grãos na maioria dos locais avaliados em cada ano, com exceção dos avaliados em 2010 (Tabela 2). Nesses genótipos, observou-se comportamento diferencial quando submetidos às várias localidades do Estado de Minas Gerais, evidenciado pelo efeito significativo das interações genótipo x local e genótipo $\mathrm{x}$ ano. Este fato indica que a seleção deve ser realizada em cada ambiente específico, uma vez que quando se constata esse tipo de interação pode ocorrer alteração na classificação dos genótipos de um local para outro. A interação genótipo x local só não foi significativa para os anos de 2001, 2005 e 2010. Em específico para 2005, apenas realizou-se ensaio em Leopoldina, o que inviabilizou a estimativa do componente da interação. Os ensaios de 2001 e 2010 foram realizados nos mesmos locais, Leopoldina e Prudente de Morais. Para isso, podem ser levantadas duas hipóteses: (a) por estar situadas na Zona da Mata Mineira, provavelmente as condiçóes de ambas as localidades foram similares nesses dois anos, não permitindo detectar a significância da interação genótipo x local; (b) pelo fato de se ter eliminado, mantido e renovado genótipos durante o período considerado, é possível que os genótipos avaliados em 2001 e 2010 não tenham respondido significativamente às alteraçôes do ambiente, o que resultou na não significância da interação. Contudo, em geral, os locais utilizados foram suficientemente contrastantes para identificar a variabilidade genética entre os genótipos, constatada pela significância na grande maioria dos anos avaliados, comprovando que a escolha deles foi eficaz para representar a diversidade edafoclimática em Minas Gerais.

Com relação à análise de deviance global, ou seja, dos ensaios ao longo dos anos (Tabela 2), verificou-se efeito significativo para genótipo bem como para interação genótipo $\mathrm{x}$ ano. Neste contexto, é possível constatar que a seleçáo foi viável ao longo dos anos avaliados o que permitiu a obtenção de ganhos genéticos.

De forma geral, a produtividade média de grãos dos genótipos avaliados de 1998 a 2010 aumentou, principalmente nos cinco primeiros anos (Figura 1), o que reitera o ganho em produtividade estimado para o programa durante o período em estudo. A oscilação observada no período de avaliação pode ser decorrente das mudanças, a cada ano, no grupo de genótipos avaliados. Assim, um grupo avaliado em um determinado ano pode responder diferentemente do grupo avaliado no ano anterior ou subsequente. Outra

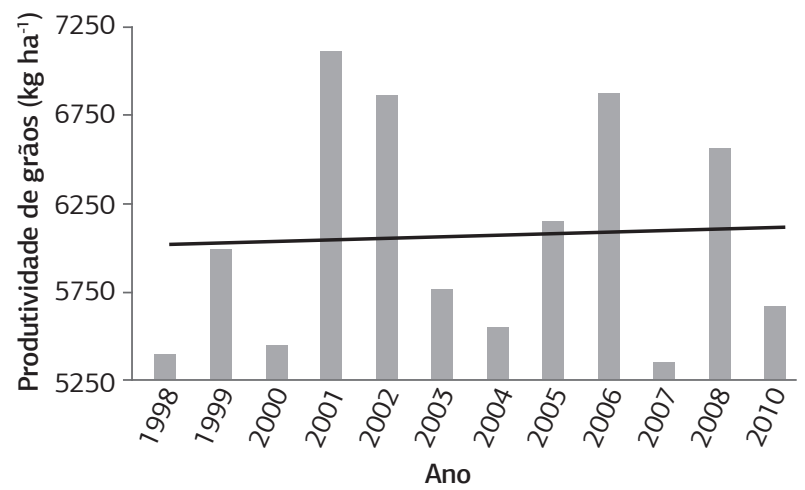

Figura 1. Regressão linear entre produtividade de grãos e ano de avaliação de genótipos do programa de melhoramento de arroz irrigado em Minas Gerais, no período de 1998 a 2010, Minas Gerais, Brasil.

Tabela 2. Valores do teste de razão de verossimilhança (LRT) ${ }^{1}$ para os efeitos de genótipo e das interaçôes genótipo x local e genótipo $\mathrm{x}$ ano, estimativas de herdabilidade no sentido amplo $\left(h^{2}\right)$, médias e coeficientes de variaçáo dos ensaios de valor de cultivo e uso (VCUs) do programa de melhoramento de arroz irrigado em Minắs Gerais, no período de $1998 \mathrm{a} 2010$, Minas Gerais, Brasil

\begin{tabular}{|c|c|c|c|c|c|c|c|c|c|c|c|c|}
\hline \multirow{2}{*}{ Efeitos } & \multicolumn{12}{|c|}{ Produtividade $\left(\mathrm{kg} \mathrm{ha}^{-1}\right)$} \\
\hline & 1998 & 1999 & 2000 & 2001 & 2002 & 2003 & 2004 & 2005 & 2006 & 2007 & 2008 & 2010 \\
\hline Genótipo ${ }^{(1)}$ & $116,79^{* * *}$ & $15,45^{* * *}$ & $100,28^{* * *}$ & $8,74^{* * *}$ & $53,05^{* * *}$ & $4,8^{* *}$ & $27,38^{* * *}$ & $26,67^{* * *}$ & $2,52^{*}$ & $15,2^{* * *}$ & $13,18^{* * *}$ & $0,08^{\text {ns }}$ \\
\hline Genótipo $x$ Local|(1) & $10,38^{* * *}$ & $26,18^{* * *}$ & $35,79^{* * *}$ & $0^{\text {ns }}$ & $5,18^{* *}$ & $12,01^{* * *}$ & $3,33^{*}$ & $0^{\text {ns }}$ & $6,46^{* *}$ & $59,99^{* * *}$ & $14,56^{* * *}$ & $0^{\text {ns }}$ \\
\hline$h_{g}^{2}$ & 0,34 & 0,05 & 0,35 & 0,13 & 0,34 & 0,008 & 0,29 & 0,31 & 0,007 & 0,03 & 0,08 & 0,01 \\
\hline Média & 5387 & 5980 & 5436 & 7097 & 6847 & 5756 & 5545 & 6136 & 6862 & 5348 & 6551 & 5661 \\
\hline CV(\%) & 15,06 & 14,54 & 13,19 & 11,19 & 9,23 & 12,86 & 12,62 & 8,52 & 13,90 & 14,19 & 11,89 & 16,03 \\
\hline
\end{tabular}

\begin{tabular}{|c|c|}
\hline Efeitos & Produtividade ( \\
\hline Genótipo(1) & $341,68^{* * *}$ \\
\hline Genótipo $\times \mathrm{Ano}^{(1)}$ & $27,87^{* * *}$ \\
\hline$h_{\mathrm{g}}^{2}$ & 0,21 \\
\hline Média & 5870 \\
\hline CV(\%) & 15,24 \\
\hline
\end{tabular}

(1) Valores obtidos pelo teste da razão de verossimilhança (Likelihood Ratio Test - LRT). Significativo a ${ }^{* * *} \mathrm{p}=0,01,{ }^{* *} \mathrm{p}=0,05,{ }^{*} \mathrm{p}=0,10$ e ns: não-significativo pelo teste $\mathrm{X}^{2}$ com 1 grau de liberdade. 
explicação pode ser embasada no diferenciado número de ambientes avaliados, uma vez que, em geral, as estimativas de rendimentos foram maiores quando se avaliaram os genótipos em um número reduzido de locais e menores quando os genótipos foram avaliados em mais ambientes. Com base nestes resultados e procurando obter estimativas de maior confiabilidade, será mobilizado o máximo de recursos para que nas avaliaçóes futuras os genótipos sejam avaliados em pelo menos três locais.

Neste trabalho, foram estimados os coeficientes de herdabilidade no sentido amplo em nível de média de locais, onde ocorreram estimativas de baixa a moderada magnitude. Esse fato decorre, principalmente, da interação linhagens x locais ter sido significativa, em razão dos efeitos de ambientes contrastantes, que proporcionam "redução" da variância genética média e, consequentemente, estimativas de herdabilidade de menor magnitude. Outro fator que deve ser considerado, é que essas herdabilidades foram estimadas por meio de equaçóes de modelos mistos, os quais geram estimativas de menor magnitude, próximas aos valores reais desses parâmetros (BoRGEs et al., 2009). Além disso, a produtividade de grãos é um caráter quantitativo, isto é, controlada por vários genes de pequeno efeito e altamente influenciada pelo ambiente (FALCONER, 1981). Assim, as baixas magnitudes das estimativas observadas no presente trabalho, podem ser devidas aos efeitos contrastantes dos ambientes avaliados, evidenciados pela presença das interaçóes genótipo x local significativas ao longo dos anos. Todavia, tanto os coeficientes de herdabilidade como os de variação experimental $(\mathrm{CV})$ estão dentro do observado para estudos com a cultura do arroz (MoraIs et al., 1997; Cordeiro, 2008), o que indica boa precisão experimental e confiabilidade das estimativas.

A dinâmica de um programa de melhoramento é quantificada pela taxa média de substituição genotípica, composta pelas taxas de inclusão, exclusão, manutenção e renovação, mensurada entre um ano de avaliação e outro (Cruz e Carneiro, 2003). A taxa média de renovação no período considerado (1998 a 2010) foi de 29\% (Tabela 3). Breseghello et al. (1999) estimaram o ganho em produtividade de grãos de arroz irrigado para a Região Nordeste do Brasil e observaram uma taxa de $27 \%$, enquanto SoAres et al. (1999), em Minas Gerais, e Aтroch e Nunes (2000), no Amapá, constataram taxas de 44\% e $46 \%$ respectivamente. Entre as linhagens modernas, as diferenças de produtividade a serem detectadas são cada vez mais estreitas. Assim, levando em consideração esse fato e comparando as taxas observadas no presente trabalho com as de outros estudos, verifica-se certo grau de similaridade. Este fator é um indicativo da contribuição do programa de melhoramento em termos de liberar cultivares, contribuindo com novas opçôes de cultivo para os agricultores. De fato é o que ocorre, pois o programa de melhoramento de arroz irrigado do Estado de Minas Gerais lança nova cultivar em um intervalo médio de dois anos.
A taxa média de manutençáo observada no programa no período considerado foi de $58 \%$ (Tabela 3), o que possibilita boa estimativa da variaçáo do ambiente entre os anos de avaliação, uma vez que o efeito do ambiente é função do contraste entre os genótipos comuns nos diferentes anos considerados (Atroch e Nunes, 2000). Assim, quanto maior o número de linhagens comuns a cada par de anos, mais acurada será a estimativa do efeito ambiental e, consequentemente, dos ganhos genéticos obtidos (Vencovsky et al., 1988). Neste contexto, em geral, o número de linhagens comuns entre um ano e outro foi superior a $50 \%$, constatado pela relação entre o número de linhagens avaliadas $(\mathrm{T})$ e mantidas $(\mathrm{M})$, com exceção para os anos de 1999 e 2000 (Tabela 4). SoAres et al. (1999) avaliaram o progresso genético em arroz de sequeiro e Atroch e Nunes (2000) em arroz irrigado e observaram taxas de manutenção de $56 \%$ e $38 \%$ respectivamente. Esses autores reportaram que taxas com essa magnitude permitem obter estimativas com alta acurácia do efeito ambiental, pois os efeitos provenientes do erro experimental e da interação genótipo x ano são, por consequência, reduzidos. Esses resultados atrelados às maiores estimativas de produtividade das linhagens substituídas (Tabela 4) evidenciam que o programa de melhoramento de arroz irrigado de Minas Gerais foi desenvolvido de forma correta e eficaz.

De acordo com método proposto por VencovskY et al. (1988), o cálculo do progresso genético pelas metodologias anteriores a essa, é perfeitamente passível de críticas. Segundo esses autores, o ideal seria a instalação dos ensaios em diferentes localidades, durante alguns anos e, com sementes renovadas de todas as linhagens obtidas pelo programa. Contudo, essas alternativas envolveriam custos adicionais altos e seria difícil de ser realizada, uma vez que muitos genótipos são descartados durante o processo de melhoramento. Também, a abordagem proposta por Moresco et al. (2004) reflete condiçóes de campo mais reais, ou seja, considera-se que, anualmente, certo número de cultivares é recomendado, mas apenas alguns

Tabela 3. Taxa de substituição de genótipos (\%) dos ensaios de valor de cultivo e uso (VCUs) do programa de melhoramento de arroz irrigado em Minas Gerais, no período de 1998 a 2010, Minas Gerais, Brasil

\begin{tabular}{|lcccc|}
\hline Anos & Inclusão & Exclusão & Manutenção & Renovação \\
\hline $1999 / 1998$ & 31 & 28 & 42 & 42 \\
\hline $2000 / 1999$ & 37 & 39 & 24 & 60 \\
\hline $2001 / 2000$ & 36 & 36 & 28 & 56 \\
\hline $2002 / 2001$ & 0 & 0 & 100 & 0 \\
\hline $2003 / 2002$ & 19 & 19 & 61 & 24 \\
\hline $2004 / 2003$ & 29 & 29 & 43 & 40 \\
\hline $2005 / 2004$ & 22 & 22 & 56 & 28 \\
\hline $2006 / 2005$ & 11 & 11 & 79 & 12 \\
\hline $2007 / 2006$ & 11 & 11 & 79 & 12 \\
\hline $2008 / 2007$ & 17 & 17 & 67 & 20 \\
\hline $2010 / 2009$ & 19 & 19 & 61 & 24 \\
\hline Média & 21 & 21 & 58 & 29 \\
\hline
\end{tabular}


agricultores os adotam, enquanto a maioria prefere usar a mesma cultivar utilizada em anos anteriores. Neste contexto, métodos alternativos, como o REML/BLUP usado neste trabalho, devem ser sempre investigados.

No processo de estimar o progresso genético e o ambiental, observou-se que as magnitudes das diferenças brutas, devido às diferenças genéticas e ambientais, variaram consideravelmente de um ano para o outro (Tabela 5). A variaçâo das diferenças brutas foi fortemente associada com as diferenças dos efeitos ambientais entre os anos. Esse fato, provavelmente, ocorreu devido à maior ou menor importância dos efeitos ambientais durante o mesmo par de anos (CARGNin et al., 2008). De acordo com estes autores, a condiçáo climática (ambiental) é o principal fator que determina a variação média de produtividade de grãos entre os anos.

As diferenças genéticas anuais também variaram consideravelmente, oscilando de -256,04 a 299,86 (Tabela 5). No entanto, observou-se que as diferenças na média de produtividade de grãos devido aos efeitos genéticos (ganhos genéticos) foram positivas em praticamente todos os anos. Este resultado pode ser confirmado pela superioridade das médias por ano das linhagens avaliadas em relação às excluídas. Além disso, o lançamento de várias cultivares durante o período considerado pode comprovar a eficiência do programa.

O progresso total, isto é, o ganho genético e ambiental do programa de melhoramento de arroz irrigado em Minas Gerais entre 1998 e 2010 foi 600,85 $\mathrm{kg} \mathrm{ha}^{-1}$. O ganho genético nesse período foi de $107,42 \mathrm{~kg} \mathrm{ha}^{-1}$, o que representa uma proporção de $17,88 \%$ da estimativa total do progresso. Esse ganho corresponde a um aumento de $8,95 \mathrm{~kg} \mathrm{ha}^{-1}$ ano $^{-1}$ obtido pelo melhoramento genético e, de acordo com o método aplicado, representa aumento de $1,99 \%$ em produtividade de grãos por ano, quando comparada à média obtida no ano referência de 1998. Esse ganho é muito próximo aos observados por SOARES et al. (1999), em arroz de sequeiro, os quais verificaram progresso genético em Minas Gerais de 1,6\% por ano; Breseghello et al.
(1999) observaram ganho genético de $0,77 \%$ ao ano, em arroz irrigado no Nordeste no Brasil e Atroch e Nunes (2000) constataram também, em arroz irrigado, o aumento de $2,45 \%$ por ano no Amapá. Assim, verifica-se que os ganhos obtidos por esse programa estáo no mesmo patamar dos alcançados por outros programas para a cultura no Brasil.

Os ganhos genéticos foram de médios a baixos, devido, provavelmente, a diversos fatores, dentre estes, é possível citar: (a) o grau de parentesco entre as linhagens testadas, uma vez que grande parte delas é originada de cruzamentos entre poucos genitores Assim, deve-se aumentar a base genética do programa, por meio da introdução de novos materiais; (b) a seleçấo ter sido realizada com base na média de locais, mesmo na presença interação

Tabela 5. Ganhos genéticos anuais e balanço do ganho genético do programa de avaliação e seleção de linhagens do programa de melhoramento de arroz irrigado em Minas Gerais, no período de 1998 a 2010, Minas Gerais, Brasil

\begin{tabular}{lccc}
\hline Anos & DB & DA & DG \\
\hline $1999 / 1998$ & 592,02 & 436,20 & 155,82 \\
\hline $2000 / 1999$ & $-543,34$ & $-287,30$ & $-256,04$ \\
\hline $2001 / 2000$ & 1660,68 & 1360,82 & 299,86 \\
\hline $2002 / 2001$ & $-249,64$ & $-249,64$ & 0,00 \\
\hline $2003 / 2002$ & $-1091,44$ & $-1085,16$ & $-6,28$ \\
\hline $2004 / 2003$ & $-211,00$ & $-191,47$ & $-19,53$ \\
\hline $2005 / 2004$ & 591,48 & 411,39 & 180,09 \\
\hline $2006 / 2005$ & 725,60 & 659,68 & 65,92 \\
\hline $2007 / 2006$ & $-1514,04$ & $-1521,68$ & 7,64 \\
\hline $2008 / 2007$ & 1203,68 & 1184,50 & 19,18 \\
\hline $2010 / 2009$ & $-890,28$ & $-943,79$ & 53,51 \\
\hline Ganhos & Média por período & Proporção & Média por ano $^{-1}$ an \\
\hline Genético & (kg ha ${ }^{-1}$ ) & $\mathbf{( \% )}$ & (kg ha $^{-1}$ ano ${ }^{-1}$ ) \\
\hline Ambiental & 107,42 & 17,88 & 8,95 \\
\hline Total & 493,43 & 82,12 & 41,12 \\
\hline & 600,85 & 100 & 50,08 \\
\hline
\end{tabular}

DB: diferença bruta; DA: diferença ambiental; DG: diferença genética (ganho genético).

Tabela 4. Número de linhagens e produtividade $\left(\mathrm{kg} \mathrm{ha}^{-1}\right)$ das linhagens novas, mantidas, excluídas e avaliadas nos ensaios de valor de cultivo e uso (VCUs) do programa de melhoramento de arroz irrigado em Minas Gerais, no período de 1998 a 2010, Minas Gerais, Brasil

\begin{tabular}{lccccccccc|} 
Anos & I & M & E & T & MI & MM & ME & MT \\
\hline 1998 & 0 & 15 & 10 & 25 & 0 & 5549 & 5145 & 5387 \\
1999 & 11 & 10 & 16 & 26 & 5971 & 6006 & 5963 & 5979 \\
\hline 2000 & 15 & 11 & 14 & 25 & 5248 & 5714 & 5218 & 5436 \\
\hline 2001 & 14 & 25 & 0 & 25 & 7114 & 7097 & 0 & 7097 \\
\hline 2002 & 0 & 19 & 6 & 25 & 0 & 6877 & 6838 & 6847 \\
\hline 2003 & 6 & 15 & 10 & 25 & 5766 & 5757 & 5753 & 5756 \\
\hline 2004 & 10 & 18 & 7 & 25 & 5513 & 5724 & 5084 & 5545 \\
\hline 2005 & 7 & 22 & 3 & 25 & 6138 & 6200 & 5667 & 6136 \\
\hline 2006 & 3 & 22 & 3 & 25 & 6876 & 6864 & 6846 & 6862 \\
\hline 2007 & 3 & 20 & 5 & 25 & 5388 & 5354 & 5323 & 5348 \\
\hline 2008 & 5 & 19 & 6 & 25 & 6603 & 6605 & 6382 & 6551 \\
\hline 2010 & 6 & 25 & 0 & 25 & 5662 & 5661 & 0 & 5661 \\
\hline
\end{tabular}

I: número de genótipos novos em relaçâo ao ano anterior; M: número de genótipos mantidos para avaliaçấo no ano posterior; E: número de genótipos excluídos da avaliaçấo no ano posterior; T: número de genótipos avaliados no ano; MI: média dos genótipos novos (renovados) em relaçâo ao ano anterior; MM: média dos genótipos mantidos para avaliaçẫo no ano posterior; ME: média dos genótipos excluídos da avaliaçâo no ano posterior; MT: média dos genótipos avaliados no ano. 
genótipo-ambiente significativa. Nesse contexto, a seleção para locais específicos é uma alternativa para maximizar a resposta à seleção, capitalizando os efeitos da interaçấo genótipo-ambiente. c) o número limitado de ensaios (locais) em alguns anos deve ter influenciado as estimativas. Assim, deve-se realizar uma estratificaçáo ambiental e aumentar o número de locais de avaliaçáo em cada regiáo de cultivo, visando à seleção mais acurada e para locais específicos; d) baixa intensidade de seleçáo e de substituição de materiais, o que pode ser facilmente contornado por meio dos ajustes nos critérios de seleção.

\section{CONCLUSÃO}

O ganho genético observado no período de 1998 a 2010 para o programa de melhoramento de arroz em Minas Gerais foi superior a $100 \mathrm{~kg} \mathrm{ha}^{-1}$. Apesar de satisfatório, novas alternativas de melhoramento podem ser empreendidas para que o incremento produtivo seja ainda maior nos próximos anos.

\section{AGRADECIMENTOS}

À Fapemig e ao CNPq, pelo aporte financeiro aos projetos de pesquisa dentro do programa de melhoramento de arroz irrigado da Epamig e pela concessão de bolsas de iniciação científica e de produtividade em pesquisa.

\section{REFERÊNCIAS}

ATROCH, A.L.; NUNES, G.H.S. Progresso genético em arroz de várzea úmida no Estado do Amapá. Pesquisa Agropecuária Brasileira, v.35, p.767-771, 2000.

BORGES, V.; SOARES, A.A.; RESENDE, M.D.V.; REIS, M.S.; CORNÉlIO, V.M.O.; SOARES, P.C. Progresso genético do programa de melhoramento de arroz de terras altas de Minas Gerais utilizando modelos mistos. Revista Brasileira de Biometria, v.27, p.478-490, 2009

BRESEGHELLO, F.; RANGEL, P.H.N.; MORAIS, O.P. Ganho de produtividade pelo melhoramento genético do arroz irrigado no Nordeste do Brasil. Pesquisa Agropecuária Brasileira, v.34, p.399-407, 1999.

CARGNIN, A.; SOUZA, M.A.; FRONZA, V. Progress in breeding of irrigated wheat for the Cerrado region of Brazil. Crop Breeding and Applied Biotechnology, v.8, p.39-46, 2008.
CORDEIRO, A.C.C. Métodos de melhoramento genético de arroz irrigado. Embrapa Roraima: Boa Vista, 2008. 65p. (Documentos 06)

CRUZ, C.D. Programa Genes: Versão Windows - Biometria. Viçosa: Editora UFV, 2006. 381p.

CRUZ, C.D.; CARNEIRO, P.C.S. Modelos biométricos aplicados ao melhoramento genético II. Viçosa: Editora UFV, 2003. 585p.

FALCONER, D.S. Introduction to quantitative genetics. 2.ed. London/New York: Longmans Green, 1981. 279p.

FRITSCHE-NETO, R.; GONÇALVES, M.C.; VENCOVSKY, R.; SOUZA JÚNIOR, C.L. Prediction of genotypic values of maize hybrids in unbalanced experiments. Crop Breeding and Applied Biotechnology, v.10, p.32-39, 2010.

MENEZES JÚNIOR, J.A.N.; RAMALHO, M.A.P.; ABREU, A.F.B. Seleçáo recorrente para três caracteres do feijoeiro. Bragantia, v.67, p.833-838, 2008.

MORAIS, O.P.; SILVA, J.C.; CRUZ, C.D.; REGAZZI, A.J.; NEVES, P.C.F. Estimação de parâmetros genéticos da população de arroz irrigado CNA-IRAT 4/0/3. Pesquisa Agropecuária Brasileira, v.4, p.421-433, 1997.

MORESCO, E.R.; FONSECA Jr., N.S.; FREIRE, E.C. Genetic gain of cotton yield in Mato Grosso State, Brazil. Beltwide Cotton Conference Proceedings. v.1, p.1100-1102, 2004.

RANGEL, P.H.N.; PEREIRA, J.A.; MORAIS, O.P.; GUIMARÃES, E.P.; YOKOKURA, T. Ganhos na produtividade de grâos pelo melhoramento genético do arroz irrigado no Meio-Norte do Brasil. Pesquisa Agropecuária Brasileira, v.35, p.1595-1604, 2000.

RESENDE, M.D.V. Genética biométrica e estatística no melhoramento de plantas perenes. Embrapa Informação Tecnológica, Brasília, 2002. 975p.

RESENDE, M.D.V. SELEGEN-REML/BLUP: Sistema estatístico e seleção genética computadorizada via modelos lineares mistos. Brasília: Editora Colombo/Embrapa Florestas, 2007. 371p.

SOARES, A.A.; SANTOS, P.G.; MORAIS, O.P.; SOARES, P.C.; REIS, M.S.; SOUZA, M.A. Progresso genético obtido pelo melhoramento do arroz de sequeiro em 21 anos de pesquisa em Minas Gerais. Pesquisa Agropecuária Brasileira, v.34, p.415-424, 1999.

SOARES, P.C.; MELO, P.G.S.; MELO, L.C.; SOARES, A.A. Genetic gain in an improvement program of irrigated rice in Minas Gerais. Crop Breeding and Applied Biotechnology, v.5, p.142-148, 2005.

VENCOVSKY, R.; MORAIS, A.R.; GARCIA, J.C.; TEIXEIRA, N.M. Progresso genético em vinte anos de melhoramento do milho no Brasil. In: Congresso Nacional de Milho e Sorgo, 16., 1986, Belo Horizonte. Anais... Sete Lagoas: Embrapa CNPMS, 1988. p.300-307. 